\title{
Polyester casts for the study of the pore structure in soils
}

\author{
H. Rogaar \\ Department of Soil science and Geology, Agricultural University, \\ Wageningen, the Netherlands
}

Accepted: 26 June 1974

\section{Summary}

The system of voids in natural soils was studied by impregnating moist samples with polyester resin and washing out the soil material after hardening of the resin. In this way a cast of the pore structure is obtained. A river levee soil, a river basin soil, and bottom sediment of the river Rhine containing mudworm burrows were chosen for the experiment. A preliminary trial was made with modelling clay to test the reliability of the method. The casts obtained as well as their stereo photographs appear to be well suited to qualitative interpretation.

In the basin soil the present meadow grass vegetation is mainly responsible for the channels in the upper soil horizons, while the unripened subsoil contains a channel system caused by a former swamp vegetation. The levee soil contains abundant voids which cannot be assigned as easily to specific single causes.

The ped structure of both soils is clearly expressed by the planes in the casts, representing the voids along ped faces.

The burrowing activity of Tubificidae is clearly shown in the casts from a pot experiment and from Rhine bottom river sediment.

Finally some suggestions are given for further application of the method.

\section{Introduction}

In sedimentology, the morphology of animal burrows has been studied by preparing polyester casts of voids in waterlogged sediments (Hertweck \& Reineck, 1967; Shinn, 1968; Förstner et al., 1968). This method is based upon the property of polyesters that they do not mix with water and have a higher specific weight. These properties enable voids in wet or waterlogged sediments to be impregnated, since the water in the voids is replaced by resin. After hardening, the non-impregnated sediment is washed away and a cast of the channels is obtained. In the morphological study of voids in soils the method seems not to have been applied so far. In order to investigate its use for soil studies some experiments with modelling clay and with natural soil samples were carried out. For this purpose the several aspects of void morphology, i.e. the diameter, shape, course and the mutual connections between channels and places, were taken into consideration.

\section{Method}

Before impregnation, the samples were saturated with water and next placed on a sandbox at a suction of $\mathrm{pF} 1$ for a few days in order to facilitate the penetration of 
Table 1. Applied methods for the removal of non-impregnated soil material.

\begin{tabular}{|c|c|c|}
\hline Material & Treatment & Results \\
\hline $\begin{array}{l}\text { Soil; ripened, calcareous } \\
\text { fluviatile loam }\end{array}$ & $\begin{array}{l}\text { dilute } \mathrm{HCl} \text { and running } \\
\text { water }\end{array}$ & $\begin{array}{l}\text { effective; results moderate } \\
\text { to good }\end{array}$ \\
\hline $\begin{array}{l}\text { Freshly sedimented calca- } \\
\text { reous loam of fluviatile } \\
\text { origin }\end{array}$ & $\begin{array}{l}\text { dilute } \mathrm{HCl} \text { and running } \\
\text { water }\end{array}$ & effective, results excellent \\
\hline $\begin{array}{l}\text { Soil; non-calcareous, } \\
\text { fluviatile basin clay }\end{array}$ & $1 \% \mathrm{H}_{2} \mathrm{O}_{2}$ and running water & effective; results moderate \\
\hline Do. & $\begin{array}{l}\text { immersion in a } \mathrm{NaCl} \text { solution } \\
\text { before application of } \\
\text { running water }\end{array}$ & not effective \\
\hline Do. & $\begin{array}{l}\text { application of sodium pyro- } \\
\text { phosphate before application } \\
\text { of running water }\end{array}$ & not effective \\
\hline Do. & $\begin{array}{l}\text { application of HF to dissolve } \\
\text { the mineral soil constituents }\end{array}$ & $\begin{array}{l}\text { some results, but the poly- } \\
\text { ester cast is also attacked and } \\
\text { becomes brittle }\end{array}$ \\
\hline Sandy soil materials & removal by running water & $\begin{array}{l}\text { variable results; many indi- } \\
\text { vidual grains are enclosed by } \\
\text { the polyster and cannot be } \\
\text { removed. }\end{array}$ \\
\hline
\end{tabular}

the polyester while preventing shrinkage of the soil mass.

The samples were than placed in carboard boxes and immersed in polyester resin. A suction of 300 to 750 mbar was applied to remove the air present in many voids. The pressure should not be reduced more than this to prevent 'boiling' of the resin and consequently possible deformation of the sample.

It appeared to be unimportant whether the suction was applied before or immediately after the immersion. The hardening period was chosen to last about four days. Hardening in a shorter time is not advisable due to the excessive heat development, which may cause explosion hazard and deformation of the samples. For the impregnation Crystic MV 1891 with an addition of $2 \%$ MEK-accelerator and 0.4 to $1 \%$ Cyclonox LNC catalyst ${ }^{2}$ was used.

After hardening of the polyester the soil material was removed by different methods, with variable results as summarized in Table 1 . The casts obtained were investigated under stereo-microscope, and recorded by stereo-photography. The photographs of Fig. $3 a, 3 c, 4 a$ and $4 b$ have been made by fixing the sample and shifting the camera over a distance of $6 \mathrm{~cm}$ in a plane parallel to the object at a distance of $34 \mathrm{~cm}$. The photographs of Fig. $2 a, 2 b, 2 c$ and $3 b$ have been made with an Aristophot photo stand (Leitz-Wetzlar). In this case the camera is fixed and the samples are lifted at one side and for the next photo at the other side in order to yield the stereo effect. The first

1 Supplied by Harjon plastics, Omoordseweg 1, Rotterdam, the Netherlands.

2 AKZO chemie b.v., Deventer, the Netherlands. 
Table 2. Summary of results of the experiments with inodelling clay.

\begin{tabular}{ll}
\hline Pore diameter & Results \\
$>1 \mathrm{~mm}$ & all pores fully recovered; diameter, form and perfection good \\
$<1 \mathrm{~mm}$ & some channels are completely lost or only partly recovered, the casts showing broken \\
& or rounded ends; diameters generally reliable, but one cast of $0.6 \mathrm{~mm} \phi$ shows a \\
& narrowing to $0.1 \mathrm{~mm}$ halfway along its lenght; pores of $0.05 \mathrm{~mm} \phi$ are recovered \\
& with a diameter of 0.025 to $0.030 \mathrm{~mm}$; form generally good
\end{tabular}

method allows photogammetric work on the pictures obtained. The latter method is unsuited for this purpose, but allows more detailed photographing. All the figures show an exaggeration of the depth perception.

The casts consist of networks of very fine filaments and are not very stable; they gradually collapse and fracture over a period of several months.

\section{Experiments with modelling clay}

Channels were made in blocks of modelling clay with the aid of iron wire and needles. Their diametres ranged from 0.05 to $2.7 \mathrm{~mm}$. The channels were open at both ends and about $3 \mathrm{~cm}$ long. The results are summarized in Table 2 and Fig. 1.

The imperfect impregnation of the finer pores is thought to be due to unremoved water, blocking the channel or being present as a film against the channel wall, influencing the diameter of the cast. This leads to the assumption that not all of the water can be replaced freely by polyester, possibly due to the blocking of the escape routes by the polyester itself, being inherent to the applied method of entrance of polyester from all sides of the blocks.

Concludingly, the method gives reliable results with pore diametres over $1 \mathrm{~mm}$. Smaller pores are more liable to imperfect impregnation and to fracturing during washing.

\section{Burrowing activities of mud-worms}

The burrowing activities of mud-worms may be of some importance in the formation of pore systems in the subsoils of fresh-water deposits (Doeksen \& Minderman, 1963). This hypothesis was tested by comparing the result of a pot test with field data. For this purpose crushed, calcareous river-loam was sedimented in glass cylinders to a height of $9 \mathrm{~cm}$. A Tubificidae population consisting of mainly Tubifex sp. and some

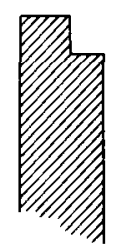

a

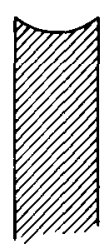

b

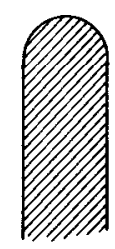

$\mathrm{C}$

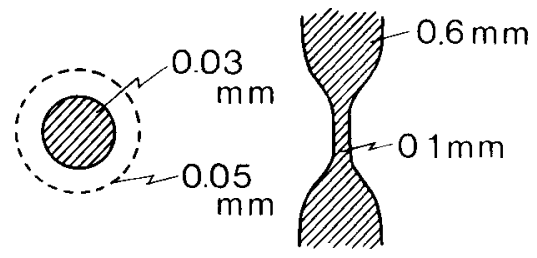

e

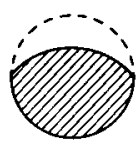

$f$

Fig. 1. Examples of defects in impregnation: a) fracture due to insufficient care in handling; b) fracture due to enclosed air bubble; c) rounded head due to non-removed water; d and e) narrowing of casts, possibly due to non-removed water; f) cross-section of horizontal channel due to insufficient inflow of resin. 

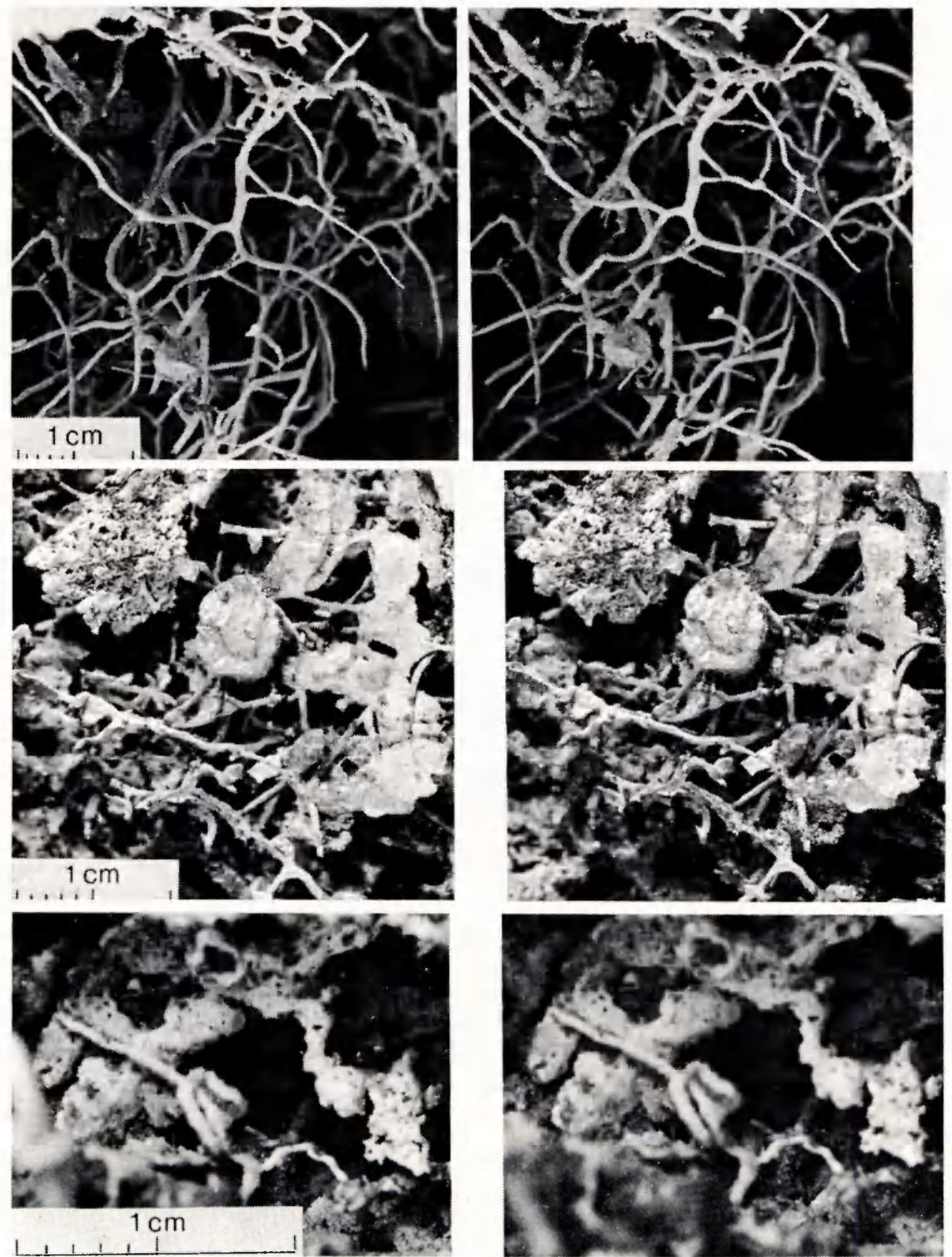

Fig. 2. Mudworm burrows:

a (top). burrows of Tubificidae; from a pot experiment;

b (middle). burrows of Tubificidae; from bottom sediment of the river Rhine;

c (bottom). burrows possibly made by annalids; from the substratum (185 cm below surface of a recent levee soil, close to the river Rhine.

Note: Fig. 2, 3 and 4 show selected parts of casts of open pores and voids in blocks of soil, the soil material around the casts having been removed by washing. These figures are stereo pairs, which should be studied with the aid of a pocket stereoscope to obtain a clear, three-dimensional image. 
Lumbriculus variegatus ${ }^{1}$ was set free on this material. The water in the cylinders was constantly refreshed by percolation. After four weeks, a system of slightly winding, interconnected channels of $0.5-0.7 \mathrm{~mm}$ diameter was formed, reaching to the bottom of the sediment (Fig. 2a). Locally the channels run into cavities of rounded or oblong shape in horizontal direction and which are flattened in vertical direction. They measure at the most $2 \frac{1}{2}$ by $9 \mathrm{~mm}$ horizontally and 1 to $2 \mathrm{~mm}$ vertically. In the pot experiment only few cavities were observed.

In bottom sediment of the river Rhine a comparable structure was found, although the cavities were more numerous and generally larger (Fig. 2b). The connecting channels are shorter than in the pot experiment. The diameters of the channels are about the same, 0.3 to $0.7 \mathrm{~mm}$. The cavities measure 1 by 1 to 6 by $8 \mathrm{~mm}$ horizontally and 1 to $2 \mathrm{~mm}$ vertically. Locally they are connected, forming chains of $1 \mathrm{~cm}$ length and more. We also tried to find back the burrows of Tubificidae in the subsoil of a river levee soil. A profile was sampled in a river cut cliff of the river Rhine, consisting of laminated, loamy material on sand. At a depth of about $185 \mathrm{~cm}$, features as shown in Fig. 2c could be traced, showing a system of large interconnected cavities and narrow, slightly winding channels. These are possibly due to annelid activity, although the forms differ from the systems shown before. These phenomena were only found at this depth.

\section{Experiments with two river-plain soils}

The subsoils of a levee soil and a flood basin soil were sampled. The levee soil is a typic eutrochrept (Anon., 1970) or 'ooivaaggrond' (de Bakker \& Schelling, 1966), situated near Ressen, Betuwe, Netherlands, mulched orchard; well drained, groundwater fluctuating between 72 and $200 \mathrm{~cm}$; large roots to $50 \mathrm{~cm}$ depth, fine roots to $140 \mathrm{~cm}$; high worm activity throughout the profile; 0 to $97 \mathrm{~cm}$ brown calcareous loam with depth grading into sand; friable; subangular blocky structure, with depth grading into a sponge structure without observable peds; lower part strongly gleyed; 97 to $140 \mathrm{~cm}$, gleyed brown calcareous clay loam, slightly sticky and plastic; spongy structure without observable peds; below $140 \mathrm{~cm}$ coarse sand with single grain structure.

The basin soil is a fluventic haplaquept (Anon. 1970) or 'poldervaaggrond' (de Bakker \& Schelling, 1966) is situated near Elst, Betuwe, Netherlands; meadow; imperfectly drained, water-table fluctuating between 20 and $90 \mathrm{~cm}$; common roots in topsoil, very few fine roots between 20 and $80 \mathrm{~cm}$; below $80 \mathrm{~cm}$ only fossil remnants of the former vegetation; low worm activity; 0 to $88 \mathrm{~cm}$ non-calcareous grey clay, increasingly sticky and plastic with depth; compound prismatic and angular blocky structure grading into smooth single prismatic; with depth strongly gleyed; 88 to $120 \mathrm{~cm}$ dark grey to black non-calcareous clay, plastic and sticky; no ped structure; with depth an increasing amount of plant remnants; from $120 \mathrm{~cm}$ peaty clay grading into clayey peat with depth.

The levee soil shows at 54 to $69 \mathrm{~cm}$ depth a pattern of thin, randomly distributed planes at short mutual distances and many fine channels (Fig. 3a). The channels are mainly between 0.05 and $0.3 \mathrm{~mm}$ in diameter, a few are about 0.4 to $0.6 \mathrm{~mm}$. Some strongly branched vertical channels are about $1.5 \mathrm{~mm}$ in diameter. At the left-hand side of Fig. 3a, the vertical burrow of an earth-worm can be seen. The finer channels are not strongly branching and only slightly winding, and there is hardly a prevalent

1 Determined by Dr L. W. G. Higler of the Governmental Institute for Nature Management (RIN), Austerlitz, the Netherlands. 

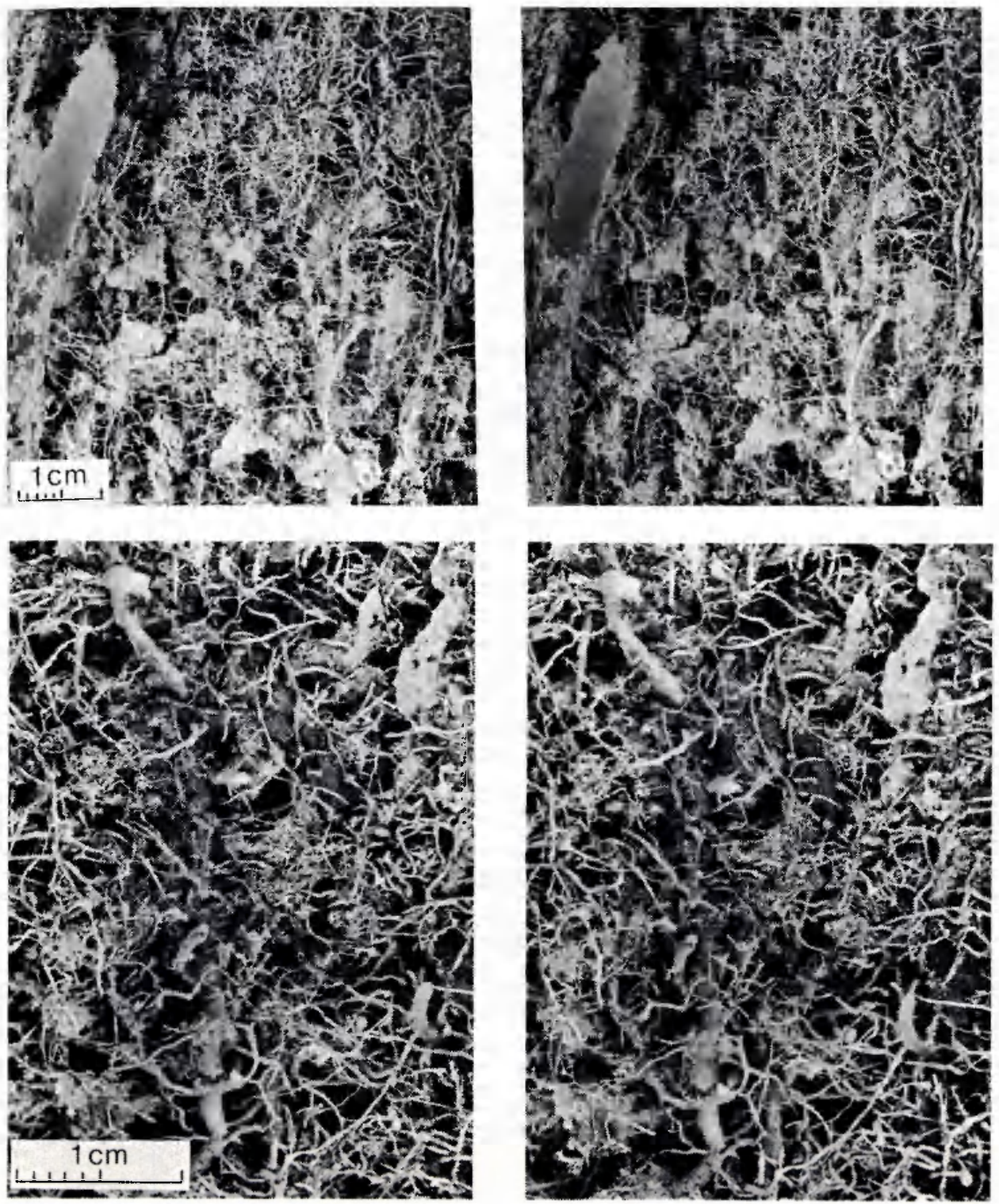

Fig. 3. Channels and planar voids in a calcareous, loamy river levee soil (see also note to Fig. 2): a (top). channels and cracks, about $60 \mathrm{~cm}$ depth; at the left an earthworm burrow is visible; $\mathrm{b}$ (bottom). channels and weakly developed planes, about $57 \mathrm{~cm}$ depth; c (top opposite page). channels in the substratum, about $110 \mathrm{~cm}$ depth. 

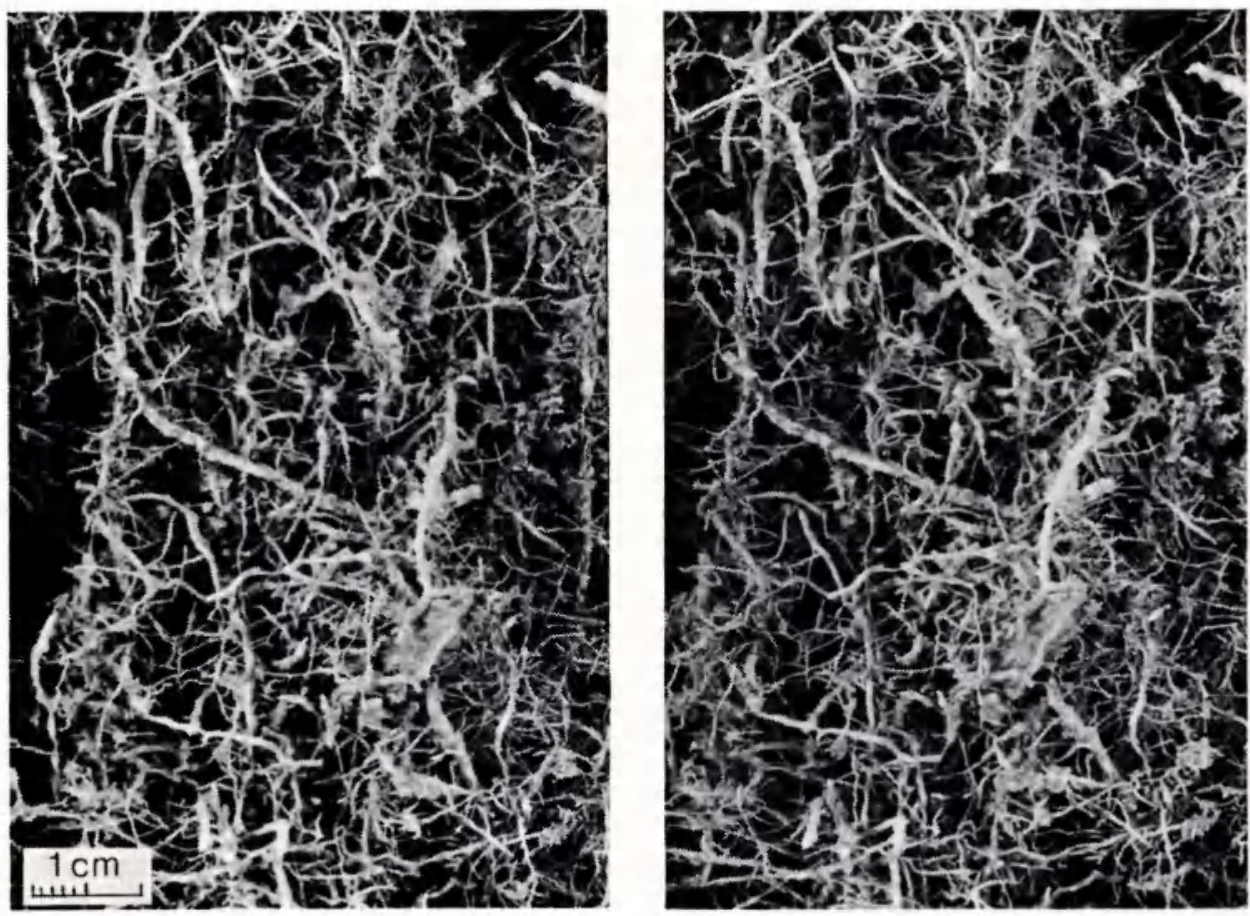

direction discernible. If any is present, it concerns the larger pores running vertically. Most of the planes in the moist sample (at pF 1) appear to be narrower than 0.025 $\mathrm{mm}$, a few could be slightly wider. The casts of the planes are pitted which is probably due to the points of contact between the neighbouring peds. As is shown in Fig. 3b, many of the planes are only very weakly expressed and show up as a network of flattened tubes rather than as a continuous face.

At a greater depth, about $110 \mathrm{~cm}$, planes are lacking (Fig. 3c). The system of channels is less intensive and consists of common vertical channels of 1 to $1.5 \mathrm{~mm}$ diameter and a randomly distributed system of fine channels, mainly between 0.1 and $0.3 \mathrm{~mm}$. The channels are less branching than at $65 \mathrm{~cm}$ depth and hardly winding. The channels are not strongly connected to each other.

The samples of the basin soil do not reveal a clear picture due to the difficulties met in washing out the soil material. In addition, some of the channels in the upper part of the profile possibly do not show up due to the presence of clayey coatings on the ped surfaces sealing off a part of the channels and preventing the entrance of the resin. At $50 \mathrm{~cm}$ depth there are widely spaced, thin planes, enclosing a system of fine channels (Fig. 4a). The planes are rather continuous and range from about 0.025 to $0.2 \mathrm{~mm}$ in thickness. They are mainly developed in a vertical direction. The channels are mainly 0.025 to $0.2 \mathrm{~mm}$ wide, hardly winding or branching. Some larger vertical channels of 0.3 to $0.4 \mathrm{~mm}$ diameter are also present. The channels are not strongly interconnected. Some are connected with the planes. In the reduced, not ripened subsoil the voids are totally different (Fig. 4b). Planes are lacking, and the main pores are vertical root channels. They are about $2.5 \mathrm{~mm}$ wide and have narrow laterals of about 0.1 to 0.2 

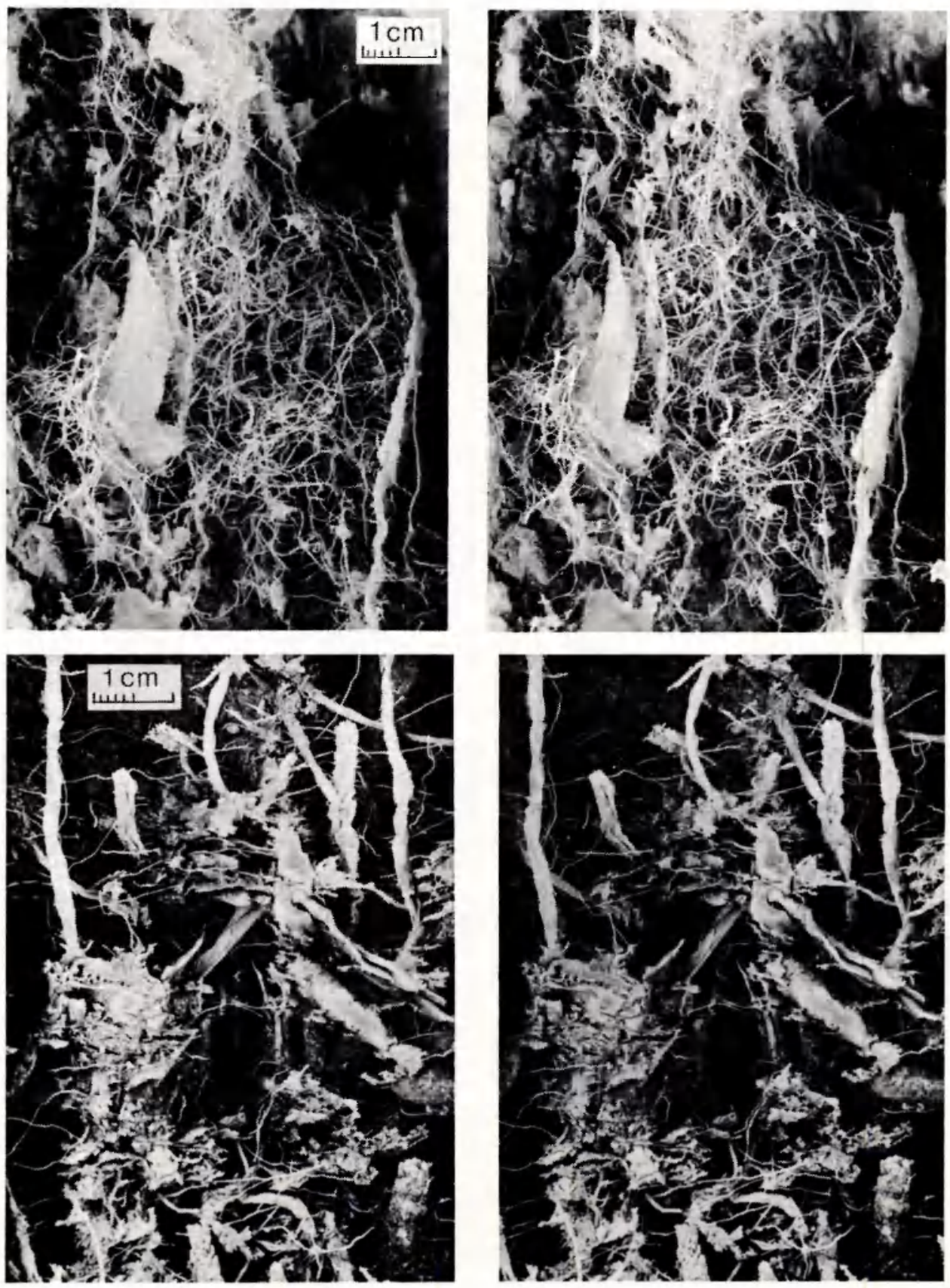

Fig. 4. Voids in a non-calcareous, clayey flood basin soil (see also note to Fig. 2):

a (top) continuous, vertical cracks enclosing a system of fine channels, about $50 \mathrm{~cm}$ below surface: b (bottom) coarse, branched channels caused by roots and 'undefined voids' in the unripened deeper subsoil. 
$\mathrm{mm}$ in diameter. Detailed study reveals also the presence of very thin $(0.025 \mathrm{~mm})$, short stubs on the casts of the lateral channels, which represent further branching. Each system of main, vertical channel with laterals is separate from the others. The larger pockets of resin, also represented in Fig. 4b, are probably other remains of the former swamp vegetation in which the silting took place. Between the examples shown in Fig. $4 a$ and $4 b$, there is a transitional zone showing features of both.

\section{Conclusions}

The method of impregnation is suitable for the study of the three-dimensional pore system in soils. Not all the voids will be represented by the casts, however, due to the fragility of the casts, the inaccessibility of some of the voids, and incomplete impregnation. Moreover casts of the finest channels may be too thin. After washing out the soil material, the structure as a whole is liable to gradual collapse, which increases the apparent density of the pore system and changes the mutual orientation of the individual components. The casts should be used qualitatively rather than quantitatively, therefore, and recorded by stereo photography within a few days or weeks.

The experiments with soil samples show differences between the pore structures of a river levee soil and a basin soil, and also differences with depth within each soil. In both cases, the pore systems are least intensive in the deepest horizons. The channels represent the traces of present and former biological activity.

In the flood basin, at $50 \mathrm{~cm}$ depth, grasses are the main agents of perforation, their primary roots giving rise to vertical, continuous channels, about $0.4 \mathrm{~mm}$ wide, each with a system of finer laterals. Via a transitional zone in which the pore structure is less intensive, this grades into a fossil structure of channels and chamberlike cavities. The pore system in this lower horizon is probably caused by the former swamp vegetation. Its morphology is closely similar to that produced by Equisetum spp. In the levee soil the lowest sample also shows some vertical anisotropy, but this is not due to grasses since the vertical channels are too large. In neither sample of the levee soil easily recognizable, single systems are found, possibly due to the interlacing of channels due to grasses, herbs and soil fauna in this well drained soil. The fine, very intensive pore system in the upper samples, however, does suggest a predominant influence of grasses at this depth.

The casts clearly show the differences in ped structure between the subangular blocky loamy, levee soil and the smooth prismatic clayey basin soil. The former has randomly distributed, narrowly spaced, discontinuous very thin planar voids, while the planes in the latter are thicker, continuous, more widely spaced and predominantly vertical. In both soils planes are lacking in the deepest horizons. The experiments with Tubificidae yielded an easily recognizable system of burrows. Neither in the levee soil nor in the basin soil such structures were found, but insufficient samples were examined to rule out the possibility of an influence of these annelids on pore formation in the lower horizons of river plain soils.

\section{Scope of the method}

Application of the method to soils appears useful in three fields:

1. In soil science education, to give students a clear idea about the voids present in 
soils. The problems of slow collapse and fracturing of the casts will need to be solved in that case. They are possibly overcome by preserving the opaque or coloured cast in a block of clear polyester.

2. In soil morphology, for the semi-detailed, qualitative study of the pore structure as shown in this paper.

3. In soil hydrology to get an impression about the presence and size of fissures in wet and moist soil materials, up to about $\mathrm{pF} 2$. For this purpose all open fissures at a certain moisture tension can be filled up with a dyed polyester. After hardening the soil can be dried and impregnated with a colourless polyester to make polished blocks or thin sections for detailed study.

\section{Acknowledgment}

I thank Mr P. J. van de Waal for technical support with the impregnation, Ing. Th. Pape and $\mathrm{Mr} \mathrm{Z}$. van Druuten for assistance with the photography, Mr G. Buurman for finishing the drawing, Miss $\mathrm{D}$. de Haas for typing the manuscript, $\mathrm{Mr} \mathrm{R}$. Brinkman and Dr S. Slager for critically reading the manuscript, and, most of all, Ing. R. P. M. Leenaars for his extensive cooperation in carrying out the experiments.

\section{References}

Anonymous, 1970. Soil taxonomy. Soil Survey Staff, Soil Conservation Service, U.S. Department of Agriculture, Washington, D.C.

Bakker, H. de \& J. Schelling, 1966. A system of soil classification for the Netherlands. Pudoc, Wageningen.

Doeksen, J. \& G. Minderman, 1963. Typical soil structures as the result of the activities of mudworms. In: J. Doeksen \& J. van der Drift (Ed.), Soil organisms. Amsterdam, 1963.

Förstner, U., G. Müller \& H. E. Reineck, 1968. Sedimente und Sediment Gefüge des Rheindeltas im Bodensee. Neues Jahrb., Mineral. Abhandl. 109: 33-62.

Hertweck, G. \& H. E. Reineck, 1966. Untersuchungsmethoden von Gangbauten und andere Wühlgefügen mariner Bodentiere. Natur u. Museum 196 (11): 429-437.

Shinn, A., 1968. Burrowing in recent lime sediments. J. Paleontol, 42: 879-894. 